\title{
LA CAPACIDAD DE LAS PERSONAS NATURALES: ANÁLISIS DEL CÓDIGO CIVIL A LA LUZ DE LA LEY GENERAL DE DISCAPACIDAD: CAMBIO DE VISIÓN DEL DERECHO CIVIL POR LOS DERECHOS HUMANOS
}

\author{
THE CAPACITY OF THE NATURAL PERSON: AN ANALYSIS OF THE \\ CIVIL CODE ACCORDING TO THE GENERAL LAW OF DISABILITY: A \\ CHANGE OF VISION OF THE CIVIL RIGHT FOR THE HUMAN RIGHTS
}

Oreste Gherson Roca Mendoza ${ }^{1}$

\section{Resumen}

El presente ensayo trata del análisis de la institución de la capacidad de las personas naturales a través del Código Civil, su cambio de modelo tradicional al modelo social para establecer la igualdad entre las personas discapacitadas de las que no lo son, en base a las normas internacionales y nacionales, empezando por la definición de la personalidad jurídica, la regulación actual de la incapacidad que es aplicable a las personas con discapacidad o deficiencia física y/o mental, la invalidez de sus actos, la curatela, e interdicción, y su contraste con el modelo social desarrollado tanto por las convenciones de derechos humanos y la Ley № 29973, Ley General de Discapacidad, así como a nivel jurisprudencial internacional como nacional, para advertir su inviabilidad y su necesaria reformulación, que ya ha sido efectuado por la CEDIS, para la implementación del sistema de apoyo.

\section{Palabras clave}

Incapacidad, discapacidad, curatela, interdicción, modelo social, CEDIS.

\section{Abstract}

This essay is about the analysis of the capacity establishment of natural persons

\footnotetext{
Abogado por la Universidad Nacional Mayor de San Marcos (UNMSM). Estudios de Maestría en Derecho Civil en la Escuela de Posgrado de la Pontificia Universidad Católica del Perú. Asesor Legal de la Dirección General de Desarrollo y Ordenamiento Jurídico del Ministerio de Justicia y Derechos Humanos. Asistente de Docencia de Derecho Civil en la Facultad de Derecho y Ciencia Política de la UNMSM. Miembro del Taller de Derecho Civil “José León Barandiarán". Colaborador permanente de Gaceta Jurídica. Miembro de la Comisión Intersectorial de Derecho Internacional Privado encargada del estudio de los temas tratados en la Conferencia de La Haya sobre Derecho Internacional Privado, mediante Resolución Ministerial № 175-2015-JUS. Secretario Técnico del Grupo de Trabajo encargado de revisar y proponer mejoras respecto a la Ley General de Sociedades, constituido por Resolución Ministerial № 0182-2014-JUS. Correo electrónico: etsero_7@hotmail.com
} 
through the Civil Code, its change of the traditional model to the social one to establish the equality between the persons who are disabled and the ones who are not, according to the international and national standards, starting by the definition of the legal personality, the current regulation of incapacity that is applied to persons who suffer from it or from physical and/or mental impairment, the invalidity of their acts, the curatorship, and interdiction, and its contrast to the social model developed by both, the conventions of human rights and the Law No. 29973, General Law of Disability, and the international and national jurisprudence level, in order to alert its failure and its needed modification, which has been carried out by the Special Committee of Inspection of the Civil Code (CEDIS), for the implementation of the support system.

\section{Key words}

Incapacity, disability, curatorship, interdiction, social model, CEDIS.

\section{INTRODUCCIÓN}

Hace un poco menos de un año recibí la invitación de participar en las Jornadas por los 30 años del Código Civil: Persona y Familia organizado por la UNIFE y el Instituto de la Familia de la Facultad de Derecho de la misma universidad y aproveché la ocasión para analizar y exponer el tema de la capacidad jurídica de las personas naturales con discapacidad debido al giro de $180^{\circ}$ grados que está sufriendo (para bien) configurándose como una figura jurídica ajena a lo que tradicionalmente nos han enseñado e incluso que a veces se siguen enseñando en las universidades y conferencias.

Ello ameritó a seguir profundizando sobre el tema de la capacidad jurídica y exponer el cambio de paradigma, que se hace necesario y oportuno por los cambios normativos que tendrá el Código Civil, producto no de una revaluación de las instituciones civiles (de raíces romanísticas) por los civilistas sino que proviene desde el enfoque de los derechos humanos a través de organismos internacionales.

\section{PUNTO DE PARTIDA: LA PERSONALIDAD JURÍDICA Y LA CAPACIDAD JURÍDICA}

La personalidad jurídica confiere al ser humano ser reconocido como persona ante la ley, y en estricto, a ser tratado como sujeto de derecho, y que por ello pueda tener la capacidad de ser titular de situaciones jurídicas subjetivas y asimismo ejercerlas. 
Entonces, esta capacidad "jurídica" está ligada consustancialmente al sujeto de derecho, y por ende al ser humano. Por tanto, al reconocerse al ser humano personalidad jurídica, también debe permitirse su manifestación que es la capacidad jurídica.

Así, la capacidad jurídica es la aptitud para ser titular de situaciones jurídicas y poder ejercerlas, por parte de los sujetos de derecho, que les reconoce el ordenamiento jurídico. "Adquirir capacidad jurídica significa devenir en sujetos de derecho; es decir, destinatarios de las normas elaboradas por el ordenamiento jurídico en función sustancialmente protectiva" (GAZZONI, Francesco, 1998, p. 119).

Entonces, "designa la posición general del sujeto en cuanto destinatario de los efectos jurídicos. Por su naturaleza los efectos jurídicos, que se resuelven en modo de comportamiento, se coligan necesariamente a un sujeto: el cual deviene así autorizado u obligado al comportamiento previsto por la norma" (FALZEA, 1985, p.147).

Hay una clasificación de la capacidad jurídica que es la desarrollada en Francia: capacidad de goce y capacidad de ejercicio, siendo que en este último se subclasifica (según la doctrina alemana, seguida por Italia y algunos franceses) en capacidad negocial, capacidad de imputación o delictual y capacidad procesal (ESPINOZA, 2004, p.525).

Esta clasificación francesa ha sido tomada por nuestro Código Civil. En dicha línea, la capacidad de goce es entendida como aptitud para ser beneficiado de derechos y asumir deberes, o sea, ser titular de situaciones y relaciones jurídicas. Debido a que coincide con la subjetividad jurídica (ser sujeto de derecho implica gozar de por sí de derechos) se ha indicado que resulta innecesario, situación distinta cuando se refiere a capacidad de ejercicio porque no todos lo tienen (ESPINOZA, 2004, p. 525 y 526).

Considero que ello resulta incorrecto debido a que se partía que los sordomudos o retardados mentales no podían ejercer sus derechos por sí mismo, que conllevaba a sustentar que capacidad de goce es consustancial al sujeto de derecho mientras que la capacidad de ejercicio no; sin embargo, debido al cambio de paradigma (seguidamente a explicarse) todos tienen capacidad de goce y de ejercicio sin distinción alguna. Ello implica que la observación de innecesaridad sobre la capacidad de goce ya no tendría sustento, porque lo mismo se diría de la capacidad de ejercicio. 
Por otra parte, la capacidad de ejercicio significa "capacidad de realizar actos jurídicamente relevantes, incidentes sobre sus propios intereses" (ALPA y BESSONE, 1990, p. 72); esto es, aptitud para ejercer sus derechos, cumplir sus obligaciones, defenderse en procesos judiciales, asumir responsabilidad, la cual se obtiene progresivamente en tanto se aumenta la edad completándose cuando se cumple dieciocho años de edad (varía según los países).

El punto álgido y materia de análisis en la presente investigación es justamente esta capacidad, ya que si bien se completa con la mayoría de edad se han establecido diversas excepciones para negar tal capacidad a ciertas personas que están afectadas por un mal sea físico o mental y por ende ser objeto de segregacionismo en todos los niveles, partiendo de que son incapaces de llevar una vida en relación.

\section{EL ESQUEMA TRADICIONAL DEL BINOMIO CAPACIDAD - INCAPACIDAD Y SU REGULACIÓN EN EL CÓDIGO CIVIL PERUANO}

\subsection{CAPACIDAD E INCAPACIDAD}

A nivel legislativo, pasando por alto la Constitución Política del Perú (1993) por ser expedida posteriormente, el Código Civil (1984) establece en su artículo $1^{\circ}$ que "toda persona tiene el goce de los derechos civiles, salvo las excepciones establecidas por ley" lo cual obviamente es incorrecto porque como se había indicado anteriormente ser titular de situaciones jurídicas es inherente al ser humano y no admite excepciones, siendo toda regulación en contrario inconstitucional.

Por otra parte, el artículo $42^{\circ}$ del Código Civil señala que "tienen plena capacidad de ejercicio de sus derechos civiles las personas que hayan cumplido dieciocho años de edad salvo lo dispuesto en los artículos $43^{\circ}$ y $44^{\circ \prime \prime}$. Al respecto, al hacer referencia a "plena" capacidad de ejercicio se está reconociendo que existe dicha capacidad desde antes pero que poco a poco se forma y que llega a su plenitud a los 18 años de edad. Ello tiene su sustento en diversas normas que reconocen capacidad de ejercicio a menores de edad para determinados actos de autonomía privada.

Por el contrario, las personas que se encuentran comprendidas en los supuestos de los artículos $43^{\circ}$ y $44^{\circ}$ son consideradas incapaces, sea por un dato objetivo como la edad o por un dato subjetivo como la deficiencia física o mental. 
Al respecto, la incapacidad aludida se conoció ya en las legislaciones antiguas, especialmente en los casos de enfermedad mental y de prodigalidad (OERTMANN, 1933, 67). Se señalaba de forma absoluta que las personas incapaces "dado que, por carecer de capacidad negocial, no pueden atender por sí mismos a sus relaciones jurídicas, necesitan de otras personas que lo hagan en su lugar y en interés de los mismos" (LARENZ, 1978, p. 106)

Incluso se indicó que "las normas que establecen la capacidad y las correspondientes causas de incapacidad son de orden público y, por consiguiente, inderogables. Por lo demás, cualquier pacto realizado por el incapaz acerca de su capacidad estaría afectado el mismo del vicio de incapacidad" (CARIOTA FERRARA, 1956, p. 524), aunque señaló también que la persona incapaz parcialmente se provee de la cooperación de otra persona (curador) que obra juntamente con el incapaz (CARIOTA FERRARA, 1956, p. 525), lo cual no fue tomado en cuenta en las doctrinas posteriores.

Asimismo, cuando una persona se le "acusa" de incapaz las personas de su entorno pueden someterla a un interdicto para "reconocer" su falta de voluntad y por ende ser reemplazados por otra persona para que realice los actos por él, debido a que "los interdictos por enfermedad mental son incapaces de llevar a cabo cualquier negocio jurídico, ya sea de derecho de familia o de derecho patrimonial, o bien entre vivos o por causa de muerte; porque el fundamento de la incapacidad legal en esta hipótesis es tal, que, si realmente existe, importa asimismo incapacidad de querer, y por tanto, imposibilidad natural de hacer cualquier manifestación de voluntad" (COVIELLO, 1938, p. 377).

Dicha ideología se ha mantenido hasta finales del siglo $X X$, en que aún se señalaba que frente a deficiencias mentales o físicas procedía la interdicción e inhabilitación (Italia), dejando al interdictado solo actos de mera administración y el resto al curador, de lo contrario serían anulables (ALPA y BESSONE, 1990, p. 75-76).

A nivel nacional, se justifica dicho esquema que se regula en el Código Civil señalándose que la capacidad responde a la libertad pero la capacidad de ejercicio sí puede estar restringida en la medida que ésta no atañe a la esfera del ser humano en cuanto tal (PRIORI, 2004, p. 157), sino sólo "con la envoltura o instrumental sicosomático del que se vale el ser humano para realizarse" (FERNANDEZ, 1995, p. 124). 
No obstante, a nivel comparado, por ejemplo Italia, el régimen ha sido modificado mediante la Ley № 6/2004, que ha introducido "medidas de protección de las personas privadas en todo o en parte de autonomía", por la crítica del régimen de interdicción rígido y presuponer los actos válidos y prohibidos. Así, se ha introducido un nuevo instituto: La administración de apoyo que "es un sistema de tutela más articulado y flexible en la búsqueda de un equilibrio entre dos exigencias de fondo: la garantía de la libertad de la persona y su protección" (PARADISO, 2012, p. 68) aplicable a las personas que tienen una disminución física o psíquica que imposibilita proveer sus propios intereses. "La administración de apoyo es, entonces, un nuevo instrumento de protección de sujetos débiles; y el principio general que gobierna esta innovación es el respeto a la dignidad de la persona, el cual la Constitución italiana" (GRONDONA, 2015, p. 62).

\subsection{DISCAPACIDAD: DEFICIENCIA FÍSICA Y MENTAL}

La Primera Encuesta Nacional Especializada sobre DISCAPACIDAD 2012 ha señalado que el 5,2\% de la población nacional (1 millón 575 mil 402 personas) padecen de algún tipo de discapacidad o limitación física y/o mental. Esta condición afecta, en mayor proporción, a la población de 65 y más años $(50,4 \%)$ y de 15 a 64 años $(41,3 \%)$.

Respecto a las personas con deficiencia física se establecía que los sordomudos, los ciegosordos y los ciegomudos que no pueden expresar su voluntad de manera indubitable, eran incapaces absolutos esto es, no tenían capacidad de ejercicio, y por tanto sus actos eran nulos (matrimonio, testamento, contratos, como compraventa, donaciones), porque por sí mismos su voluntad (que existía) no se exteriorizaba por los medios ordinarios al "común de las personas". (El numeral 3 del artículo 43, el numeral 4 del artículo 241, el artículo 693, el artículo 694 y el numeral 2 del artículo 705 del Código Civil, actualmente derogados, y el inciso 2 del artículo $274^{\circ}$ aún vigente inexplicablemente).

Un ejemplo de deficiencia física es la esclerosis lateral amiotrófica: Enfermedad degenerativa de tipo neuromuscular, que lo tiene Stephen Hawking.

Asimismo, respecto a las personas con deficiencia mental se establecía o aún se establece que no tienen capacidad natural (absoluta o relativa). De ahí que el acto de autonomía privada es nulo cuando la parte celebra con incapacidad natural absoluta o es anulable cuando la parte celebra con incapacidad natural relativa. 
En efecto, el numeral 2 del artículo $43^{\circ}$ del Código Civil establece que los privados de discernimiento son incapaces naturales absolutos, que es un presupuesto de la capacidad de obrar o de ejercicio. Si no hay capacidad natural obviamente no podrá tener capacidad de obrar.

Por otro lado, la incapacidad natural relativa comporta una disminución de la voluntad y no su ausencia. Los retardados mentales y los que adolecen de deterioro mental que les impide expresar libremente su libertad (numeral 3 del art. 43 del (C), son incapaces naturales relativos.

Hay una excepción referida a los incapaces de obrar con discernimiento o con capacidad natural. Ellos podrán celebrar contratos vinculados con las necesidades ordinarias de su vida diaria (artículo 1358o del Código Civil), pero esto estuvo pensado en menores de edad con discernimiento, ebrios habituales, toxicómanos, que tienen una incapacidad legal, pero tienen capacidad natural, pero no para que tienen deficiencias mentales porque tenían alterado su discernimiento.

Un ejemplo de deficiencia psíquica es la esquizofrenia (como tiene John Nash) que en la mayoría de los casos aparece por primera vez en los hombres en los últimos años de la adolescencia, o entre los 20 y los 25 años. En las mujeres, la esquizofrenia suele aparecer por primera vez entre los 20 y los 35 años ${ }^{2}$.

En ese supuesto se parte de la premisa que no tienen capacidad natural o si la tuviere es parcial ya que hay casos en que el débil mental puede controlar suficientemente negocios sencillos o cotidianos y actuar en libre determinación de voluntad, mientras que fracasa tratándose de negocios complejos o inusuales no pudiendo tomar decisiones como una persona "normal" (FLUME, 1998, 232).

\subsection{CURATELA E INVALIDEZ DE LOS ACTOS DEL “INCAPAZ"}

Bajo tal contexto, se incide que el modelo de regulación de la capacidad jurídica de las personas con discapacidad mental en el Código Civil, expresado en los artículos 43.2 ("privados de discernimiento"), 44.2 ("retardados mentales") y 44.3 ("aquellos que adolecen de deterioro mental que les impide expresar su libre voluntad"), persigue uno que opta inexorablemente por negarles "estado de lucidez" (integri status) conforme a una declaración de incapacidad (capitis diminutio) (LEÓN, 1991, p.125-126).

\footnotetext{
Disponible en internet http://nyp.org/espanol/library/mentalhealth/schiz.html. Consultado el 15 de agosto de 2015.
} 
Advertida o acusada de incapaz a una persona, su cónyuge, sus parientes o

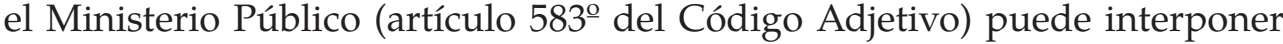
un demanda de interdicción (artículo 581ํํㄹ del Código Procesal Civil). Para ello deberán presentar la certificación médica sobre el estado del presunto interdicto, la que se entienda expedida bajo juramento o promesa de veracidad, debiendo ser ratificada en la audiencia respectiva (numeral 2 del artículo 582ํㅡㄹ del Código Procesal Civil).

Ello conllevará a que las personas juzgadas como incapaces (que no puedan dirigir sus negocios o no puedan prescindir de cuidados y socorros permanentes o amenacen la seguridad ajena, conforme el artículo $571^{\circ}$ del Código Civil) se encuentren sujetas a curatela (artículo 564ํㅡㄹ Código Civil) designándoles un curador (que ellos mismos no pueden nombrar). Dicho curador es una persona adulta con plena capacidad de ejercicio (artículo $568^{\circ}$ del Código Civil).

De lo indicado se puede deducir que tener una deficiencia mental per se no te sujeta a tener un curador, ya que debe cumplirse las condiciones del artículo $571^{\circ}$ del Código Civil, por ello están y deben estar excluidas de la curatela las personas con discapacidad mental que puedan dirigir sus negocios, cuidarse por sí mismas y que no amenacen la seguridad ajena. Ello implica que estas personas no sean representadas ni asistidas, lo cual no debería excluir que puedan contar con un tipo de apoyo para realizar sus actos negociales.

Por otro lado, los artículos $45^{\circ}$ y $576^{\circ}$, parten de la representación del incapaz por el curador, quien ejerce sus derechos civiles, que para "protegerlo" puede internarlo en un centro de restablecimiento, según el grado de incapacidad en sus negocios, aunque tendencialmente se refiere a todos.

El artículo $576^{\circ}$ del Código Civil señala entre las funciones del curador, la de "representar o asistir" a la persona con discapacidad en sus negocios según el grado de "incapacidad", aunque tienden a otorgar representación, y no especificar qué actos intervendrá el curador, sino una afirmación genérica, por lo que la curatela es de carácter representativo que suple la actuación del interdictado.

Al declarar la interdicción del incapaz, el juez fija la extensión y límites de la curatela según el grado de incapacidad de aquél (artículo 581º del Código Civil) lo cual como se ha indicado se hace de forma genérica o según lo que diga el médico, y los actos anteriores a la interdicción pueden ser anulados si la causa de ésta existía notoriamente en la época en que se realizaron (artículo 
$582^{\circ}$ del Código Civil). Cabe anotar que este dispositivo no distingue si esta consecuencia es en función al grado de incapacidad mental que tiene el interdicto, lo cual debería ser interpretado en concordancia con el artículo $576^{\circ}$ del Código Civil. Esto determina que la anulación no procederá sobre los actos realizados por el interdicto cuando su grado de incapacidad no haya limitado su voluntad sobre los mismos.

Por último, la persona con discapacidad interdictada puede rehabilitar sus derechos a pedido de él mismos, curador, o quien afirme tener interés y legitimidad para obrar (artículo 854ํํำ del Código Procesal Civil). Hasta que ese momento llegue, ni siquiera tienen domicilio porque conforme el artículo $37^{\circ}$ tienen por domicilio el de sus representantes legales.

En efecto, no tienen las personas con deficiencia mental interdictados alguna facultad de ejercer sus derechos o celebrar actos, que sean nulos (numeral 2 del artículo $219^{\circ}$ del Código Civil) o anulables (numeral 1 del artículo $221^{\circ}$ del Código Civil), siendo sustituidos por sus curadores que hacen de representantes legales (artículo 45ํํํㄹ del Código Civil).

Aquí cabe hacer presente el artículo $226^{\circ}$ del Código Civil que "La incapacidad de una de las partes no puede ser invocada por la otra en su propio beneficio, salvo cuando es indivisible el objeto de la obligación común", el cual no distingue a qué tipo de incapacidad se refiere y más importante que dicho artículo parte de que la incapacidad conlleva a una alegación de algún cuestionamiento del negocio jurídico sin tener en cuenta si ello resulta por sí justificado de acuerdo al grado de discapacidad, siendo las objeciones múltiples (LEON, 2015, 50).

A nivel de deberes, cuando se refiere a daños resarcibles, la incapacidad de discernimiento o natural comporta la exoneración del incapaz de la responsabilidad por el daño inferido por su acto, salvo la eventualidad de pagar un resarcimiento equitativo por la imposibilidad de que lo pague quien estaba obligado a su "vigilancia".

Existen asimismo hipótesis de que se tenga capacidad legal de ejercicio pero no capacidad natural, que implica anulabilidad de sus actos, lo que confirma "que los dos tienen carácter general y se completan recíprocamente" (BRECCIA, Umberto; BIGLIAZZI GERI, Lina; NATOLI, Ugo, y BUSNELLI, Francesco, 1992, p.148). 
De lo antes indicado se puede señalar que el Código Civil opta por dos modelos de atribución de incapacidad: (i) el modelo de atribución directa por estatus y (ii) el modelo funcional.

El modelo de atribución directa por estatus supone la existencia de tres elementos: una deficiencia, principalmente mental o intelectual; una sentencia judicial y la imposición de una interdicción (BARIFFI, 2011, p. 298). En este sentido, se atribuye incapacidad porque la legislación dispone que tengan inaptitud para ejercer válidamente negocios jurídicos y, por el proceso de interdicción que básicamente afirma los resultados de un examen médico (basta que alegue algún mal mental) que se adjunta a la demanda de interdicción (artículo $582^{\circ}$ del Código Procesal Civil.

Por lo tanto, existe una presunción de incapacidad general hacia las personas con discapacidad mental y, se le asigna un rol preponderante al examen médico. Asimismo, el modelo funcional se presenta en legislaciones en las que las personas con discapacidad mental son consideradas incapaces solo si, por causa de su discapacidad, no puede realizar una función específica o su aptitud para tomar decisiones es deficiente (QUINN, 2011, p. 44-45).

De esta manera, se puede afirmar que el Código Civil peruano adopta de alguna manera el modelo funcional cuando dispone que "los alcances y los límites de la curatela son fijados por el juez, cuando declara la interdicción del incapaz, en función de su grado de incapacidad" (artículo 581 del Código Civil); sin embargo, existe una innecesaria judicialización de demandas de interdicción por la sola condición que el emplazado es una persona con alguna afectación mental y en los criterios asumidos por la judicatura al pronunciarse sobre la materia, ya establece la curatela de manera indeterminada en contravención al artículo 581ํㅡㄹ del Código Civil.

Esta situación se da debido a que se parte de la idea de que la incapacidad es una categoría uniforme y que debe basarse en cuestiones estrictamente médicas para justificar la interdicción, pero es necesario señalar que existen diversos grados de afectación o discapacidad mental, presentándose casos en que la persona tiene un leve mal pero que puede expresar su voluntad aunque requiere del apoyo de un tercero que lo ayude a concretarla y otros en que se verifica una afectación tan intensa o grave requiriendo solo en ese caso que otro lo sustituya para desarrollar actos por interés del discapacitado mental o físico. 
Por lo tanto, urge un cambio de paradigma consistente en abandonar el planteamiento de la rehabilitación y adoptar un enfoque social basado en los derechos a través del cual se reconozca que las personas con deficiencia física y mental tienen capacidad jurídica (capacidad de goce y de ejercicio), y pueden tomar sus propias decisiones en todos los ámbitos de su vida.

\section{CRÍTICA AL MODELO IMPERANTE EN EL CÓDIGO CIVIL EN EL TRATAMIENTO ELEGIDO PARA LAS PERSONAS CON DEFICIENCIA MENTAL Y FÍSICA}

\subsection{LA CAPACIDAD SEGÚN EL MODELO SOCIAL}

De acuerdo a lo establecido en el artículo $4^{\circ}$ de la Convención sobre los Derechos de las Personas con Discapacidad, los Estados Partes se comprometen a asegurar y promover el pleno ejercicio de todos los derechos humanos y las libertades fundamentales de las personas con discapacidad sin discriminación alguna por motivos de discapacidad, comprometiéndose a adoptar todas las medidas legislativas, administrativas y de otra índole que sean pertinentes para hacer efectivos los derechos reconocidos en la presente Convención.

Asimismo, establece en su art. 12.2 que "los Estados partes reconocerán que las personas con discapacidad tienen capacidad jurídica en igualdad de condiciones con las demás en todos los aspectos de la vida."

En tal sentido, toda persona es capaz y en caso tenga deficiencia física o mental, se tiene que dar apoyo para que la misma persona ejerza sus actos de autonomía privada. Así, mientras el sistema tradicional tiende a un modelo de "sustitución en la toma de decisiones", como lo es la interdicción prevista en nuestro Código Civil, el vigente modelo social basado en la igualdad y en la dignidad intrínseca de las personas aboga por un modelo de "apoyo en la toma de decisiones", por lo que la presunción de la capacidad jurídica de todas las personas con discapacidad es un aspecto medular en la reforma del Código Civil. Ello significa que la discapacidad nunca debe ser motivo de una restricción y/o limitación de la capacidad jurídica pues sería discriminatorio. En esta línea, "poseer capacidad jurídica es un elemento central para la forma en que uno se agencia como persona" (BACH, 2011, p. 59).

En efecto, "el sujeto de derecho, por definición, siempre tiene capacidad por lo que no caben expresiones como personas incapaces, incapacidad absoluta o relativa sino que lo que se presenta en el ordenamiento jurídico son los 
sujetos de derecho con capacidad relativa o restringida y, plena o absoluta" (ESPINOZA, 2012, p. 876)

En este sentido, se debe asumir que las personas con discapacidad mental e intelectual tienen capacidad jurídica (la capacidad de goce y de ejercicio) y pueden tomar sus propias decisiones en todos los ámbitos de su vida, conforme al artículo $12^{\circ}$ de la Convención sobre los Derechos de las Personas con Discapacidad y al artículo $9^{\circ}$ de la Ley General de la Persona con Discapacidad, y que requieren un sistema de apoyo, definido en el numeral 3.31 del artículo 3ํํㄹ del Reglamento de la Ley № 29973, Ley General de la Persona con Discapacidad, aprobado por Decreto Supremo № 002-2014MIMP, como: Mecanismos proporcionales y adaptados a los requerimientos de la persona con discapacidad, cuyo objeto es garantizar el pleno ejercicio de su capacidad jurídica.

Ello implica determinar tipos de apoyo sobre la base del tipo de negocio jurídico, diferencias entre actos trascendentales para la vida y/o el patrimonio de la persona (matrimonio, compraventa, donación), y actos ordinarios de la vida común (reformar su casa, ir de viaje, suscribirse a un club deportivo), siendo en éste último prácticamente innecesario el apoyo.

\subsection{EL MODELO SOCIAL A NIVEL DE LA JURISPRUDENCIA CONSTITUCIONAL E INTERNACIONAL}

El Tribunal Constitucional en su Sentencia del 24 de setiembre de 2009 recaída en el STC № 2313-2009-HC/TC (fundamento jurídico 6) ha indicado lo siguiente: "La discapacidad mental no es sinónimo, prima facie, de incapacidad para tomar decisiones. Si bien las personas que adolecen de enfermedades mentales, suelen tener dificultad para decidir o comunicar tales decisiones, estas deben ser tomadas en cuenta puesto que ello es una manifestación de su autodeterminación, y en primera instancia de su dignidad. Ahora bien, el que las decisiones de las personas con discapacidad mental tengan que ser tomadas en cuenta, no implica la desaparición o la caducidad de la figura de la curatela. De acuerdo al artículo 576 del Código Civil, el curador protege al incapaz, procurando su restablecimiento y lo representa y asiste en sus negocios, según el grado de la incapacidad. Esto -que no es más que una concretización del principio de respeto de la dignidad del ser humanoimplica que el curador no debe prescindir de la voluntad del interdictado, sino protegerle en todo aquellos aspectos en donde éste no se puede valorar adecuadamente la toma de decisiones". 
Asimismo, en su Sentencia, del 11 de julio de 2008, recaída en el Expediente № STC 02480-2008-PA/TC, (fj. 13) ha reconocido a las personas con discapacidad mental como sujetos de especial protección debido a las condiciones de vulnerabilidad manifiesta por su condición psíquica y emocional, razón por la cual les concede una protección reforzada para que puedan ejercer los derechos que otras personas, en condiciones normales (sic), ejercen con autodeterminación. Este deber de especial protección se ve reflejado en la redacción del artículo $7^{\circ}$ de la Constitución Política del Perú señala que “(...) La persona incapacitada para velar por sí misma a causa de una deficiencia física o mental tiene derecho al respeto de su dignidad y a un régimen legal de protección, atención, readaptación y seguridad".

Además, la Defensoría del Pueblo ha señalado, en referencia a las personas con discapacidad mental, que "son un grupo especialmente vulnerable debido a los prejuicios sociales existentes y a la falta de su reconocimiento como sujetos de derechos" ${ }^{\prime 3}$

Por otra parte, la Corte Interamericana de Derechos Humanos en el Caso Artavia Murillo y otros (Fecundación in vitro) Vs. Costa Rica. Excepciones Preliminares, Fondo, Reparaciones y Costas, en su Sentencia de 28 noviembre de 2012 Serie C No. 257, párr. 291, ha advertido que "la discapacidad no se define exclusivamente por la presencia de una deficiencia física, mental, intelectual o sensorial, sino que se interrelaciona con las barreras o limitaciones que socialmente existen para que las personas puedan ejercer sus derechos de manera efectiva".

Lo desarrollado en dicha jurisprudencia ha pasado a un segundo nivel, generando la Convención sobre los Derechos de las Personas con Discapacidad $^{4}$ que es el primer tratado de derechos humanos que asume el modelo social. Este modelo parte de la premisa de que la discapacidad es una construcción y un modo de opresión social, y el resultado de una sociedad que no considera ni tiene presente a las personas con deficiencias. Asimismo, apunta hacia la autonomía de la persona con discapacidad para decidir respecto de su propia vida, y para ello se centra en la eliminación de cualquier tipo de barrera, a los fines de brindar una adecuada equiparación

Disponible en:

http://www.defensoria.gob.pe/modules/Downloads/informes/defensoriales/informe-defensorial-140-vf.pdf, p. 31. Consultado el 15 de agosto de 2015.

4 Adoptada por la Asamblea General de Naciones Unidas mediante Resolución A/61/611 del 13 de diciembre del 2006. Ratificada por Perú al igual que su Protocolo Facultativo mediante Decreto Supremo N 073-2007-RE, publicado el 31 de diciembre del 2007. 
de oportunidades, el tercero que "resulta ser de gran importancia, ya que demuestra síntomas del cambio desde un modelo rehabilitador a un modelo social, con su consecuente aproximación en el ámbito del Derecho, de la discapacidad como una cuestión de derechos humanos" (PALACIOS, 2008, p. 220).

Cabe precisar que el Tribunal Constitucional en su Sentencia de fecha 25 de abril de 2006 recaída en el Expediente acumulado $\mathrm{N}^{\circ} 0025-2005-\mathrm{PI} / \mathrm{TC}$ y 0026-2005-PI/TC ${ }^{5}$ (fj 26) ha sostenido que los tratados internacionales sobre derechos humanos no sólo conforman nuestro ordenamiento sino que, además, detentan rango constitucional, lo cual implica que, en coherencia con la Cuarta Disposición Final de la Constitución Política del Perú existe la obligación de interpretar los derechos y las libertades reconocidos constitucionalemente, de conformidad con el contenido de tales tratados. Por tanto, el Estado tiene la obligación de interpretar el artículo $7^{\underline{0}}$ de la Constitución -que reconoce el derecho al respeto de la dignidad y a un régimen legal de protección, atención, readaptación y seguridad de la persona con discapacidad-, de conformidad con todos los preceptos de dicha Convención.

Sobre el particular, la Corte Interamericana de Derechos Humanos en su Sentencia de fecha 31 de agosto de 2012, respecto al caso Furlán y familiares vs. Argentina, Serie C, n 246, párr. 13, ha señalado que: “en la CIADDIS y en la CDPD se tiene en cuenta el modelo social para abordar la discapacidad, lo cual implica que la discapacidad no se define exclusivamente por la presencia de una deficiencia física, mental, intelectual o sensorial, sino que se interrelaciona con las barreras o limitaciones que socialmente existen para que las personas puedan ejercer sus derechos de manera efectiva".

Pues bien, para este modelo social que tiene rango internacional (Convención) y nacional (Ley $\mathrm{N}^{\circ}$ 29973) todas las personas con discapacidad tienen plena capacidad jurídica (de ejercicio) en igualdad de condiciones con las demás en todos los aspectos de la vida. Consecuentemente, el Estado se encuentra obligado a implementar un "modelo de apoyo" en el ejercicio de la capacidad jurídica de ejercicio que evite la sustitución en la toma de decisiones de la persona con discapacidad bajo el entendido que son capaces de tomar decisiones y de conocer las consecuencias de las mismas.

Disponible en: http://www.tc.gob.pe/jurisprudencia/2006/00025-2005-AI\%2000026-2005-AI.html. Consultado el 15 de agosto de 2015 . 
Así el numeral 9.1 de la citada Ley $N^{\circ} 29973$ que la persona con discapacidad tiene capacidad jurídica en todos los aspectos de la vida, en igualdad de condiciones que las demás y establece que el Código Civil regula los sistemas de apoyo y los ajustes razonables que requieran para la toma de decisiones, lo cual implica una profunda modificación eliminándose el modelo tradicional civilista romanístico, ya que está en contra del modelo social.

\subsection{LA INCAPACIDAD, CURATELA E INTERDICCIÓN EN CONTRA DEL MODELO SOCIAL}

En efecto, el modelo social adoptado por la Convención sobre los Derechos de las Personas con Discapacidad (artículo 12), así como por la Ley $\mathrm{N}^{\circ}$ 29973, Ley General de Personas con Discapacidad (artículo 9), reconoce que las personas con discapacidad: a) tienen derecho al reconocimiento de su personalidad jurídica; b) tienen derecho al reconocimiento de su capacidad jurídica en igualdad de condiciones en todos los aspectos de la vida; c) tienen derecho de acceso al apoyo que puedan necesitar en el ejercicio de su capacidad jurídica; y, d) tienen derecho a que el Estado vele por el establecimiento de salvaguardias adecuadas y efectivas orientadas al respeto de sus derechos, voluntad y preferencias así como a impedir los abusos en relación al ejercicio de este derecho.

En tal sentido, se aprecia que la regulación actual regulada en el Código Civil y el Código Procesal Civil desarrollado líneas atrás y lo tratado como modelo social tiene caminos opuestos teniendo por jerarquía normativa modificar nuestros códigos.

Vale precisar, que la Disposición Complementaria Derogatoria de la Ley $\mathrm{N}^{\circ}$ 29973 citada eliminó de la lista de incapaces absolutos a los sordomudos, los ciegosordos y los ciegomudos que no pueden expresar su voluntad de manera indubitable y, por otro lado, el artículo 43 y 44 del Código Civil establece la posibilidad de interdictar a otros sujetos, cuya situación particular debe ser objeto de un análisis aparte.

Es posible advertir que la terminología empleada en el Código Civil alude a la persona sujeta al proceso de interdicción como "incapaz", lo cual resulta contrario al artículo $12^{\circ}$ de la Convención antes acotada que parte de la premisa que todas las personas con discapacidad tienen capacidad jurídica en igualdad de condiciones en todos los aspectos de la vida. El efecto jurídico de negación de la capacidad jurídica que conlleva el proceso de interdicción es confirmado por el inciso 1 del artículo $33^{\circ}$ de la Constitución Política del 
Perú que, sin hacer referencia específica a las personas con discapacidad, establece que el ejercicio de la ciudadanía se suspende "por resolución judicial de interdicción".

Asimismo, el modelo social promueve un sistema de apoyo a favor de la persona con discapacidad a partir del cual sea esta la que finalmente adopte una determinada decisión. Así expuesto, la facultad del curador de "proveer en lo posible (el) restablecimiento" de la persona con discapacidad se sustenta en una base médica rehabilitadora en que el principal objetivo es de alguna manera curarla para que pueda desenvolverse dentro de los parámetros de la "normalidad", lo cual hace depender la capacidad a una rehabilitación, que pudiera no ocurrir, ya que hay enfermedades que son incurables lo que no obsta a que tenga capacidad de decidir y actuar por sí mismo pero no es tomada en cuenta.

Lo que pasa es que el Código Civil y parte de la doctrina parte de basarse en la clasificación médica y sus definiciones (trastornos mentales según la Organización Mundial de Salud), para seguir tratando a los discapacitados como incapaces, y que le Estado debe tutelar el derecho a la salud del enfermo de mente, lo cual en parte como política de salud es atendible pero no a nivel de política social, ya que no puede tratarse al enfermo de salud como también enfermo social, y menos que un informe pericial médico diga lo que tiene o no tiene que hacer.

De igual forma, resulta incorrecto que una de las funciones del curador sea "colocar a la persona considerada incapaz en un establecimiento adecuado de ser necesario" pues admite los internamientos involuntarios, práctica contraria a la libertad personal y a la capacidad jurídica de estas personas.

La última frase del artículo $576^{\circ}$ del Código Civil señala entre las funciones del curador la de "representar o asistir" a la persona con discapacidad en sus negocios según el grado de "incapacidad". Si bien una lectura conjunta de dicha norma con el artículo 581 ${ }^{\circ}$ del Código Civil podría ajustarse a un modelo de apoyo en la toma de decisiones, en la práctica judicial las resoluciones de interdicción que nombran un curador no detallan los actos en que este deberá intervenir y lo realizan incluso sobre personas que no requieren curador a pesar de tener alguna deficiencia mental, porque no interfiere con sus actos de autonomía privada.

Un ejemplo de que la judicatura parte del binomio absoluto de "o eres capaz o no lo eres" se puede citar la sentencia de primera instancia del 
Décimo Segundo Juzgado de Familia de Lima de fecha de 10 de febrero de 2009, sobre la demanda de interdicción interpuesta por los hijos Francisco Antonio Gregorio Tudela Van Breugel-Douglas y Juan Felipe Gaspar José Tudela van Breugel-Douglas contra su padre Felipe Tudela Barreda que dispone lo siguiente:

“(...) FUNDADA la demanda de Interdicción interpuesta a fojas 25 a 30 en consecuencia de se declara interdicto a Felipe Tudela Barreda, por incapacidad absoluta de ejercicio, nombrándose curadores del mismo a sus hijos FRANCISCO ANTONIO GREGORIO TUDELA VAN BREGUELDOUGLASyJUANFELIPEGASPARTUDELAVANBREGUEL-DOUGLAS quienes ejercerán dicho cargo en forma conjunta y/o indistintamente; consentida o ejecutoriada que sea la Presente Resolución; cúrsense los partes pertinentes al registro personal de los Registros Públicos de Lima y Callao para en su inscripción correspondiente, y de conformidad con lo dispuesto en el inciso 1 del artículo 408 del CPC. Elévese en consulta los autos al superior Jerárquicos, en caso de no ser apelada, con la debida nota de atención, sin costas ni costos del proceso; NOTIFICANDOSE".

En el presente caso se alegó "demencia senil en curso progresivo", y que por ello era incapaz absoluto, lo cual resulta incorrecto porque justamente su progresividad implicaba un cambio constante, lo que conllevaba a que la ayuda sea progresiva y no sustitutiva desde el inicio, además la noción de incapacidad absoluta (desfasada totalmente y contraria a la Convención y a la Ley $\mathrm{N}^{\circ} 29973$ ) conlleva a que se deje a merced de terceros sin cuestionar ello. Por último, si bien en los considerandos invoca el artículo $576^{\circ}$ del Código Civil no lo aplica al momento de sentenciar.

En tal escenario, en el cual la legislación y jurisprudencia aplican un régimen de por sí seudopaternalista y que en el fondo es discriminador, en abril de 2012, el Comité sobre los Derechos de las Personas con Discapacidad de Naciones Unidas recomendó al Estado peruano que "25. (...) derogue la práctica de la interdicción judicial y revise las leyes que permiten la tutela y la curatela con objeto de garantizar su plena conformidad con el artículo 12 de la Convención. Le recomienda también que adopte medidas para cambiar el modelo de sustitución en la toma de decisiones por uno de apoyo o asistencia a las personas con discapacidad en esa toma de decisiones que respete su autonomía, voluntad y preferencias. 26. Preocupa al Comité que el Código Civil del Estado parte no reconozca la capacidad para ejercer el derecho a contraer matrimonio de las personas sordomudas, sordociegas y ciegomudas, así como de las personas con discapacidad mental o que sufren deterioro mental. 27. El Comité insta al Estado parte a que modifique el Código Civil con el fin 
de garantizar adecuadamente a todas las personas con discapacidad el ejercicio de sus derechos civiles, en particular el derecho a contraer matrimonio"6.

A mayor abundamiento, es posible encontrar otras disposiciones del Código Civil que permiten concluir que la regulación de las figuras de la interdicción y curatela converge en un modelo de sustitución en la toma de decisiones negándose a las personas con discapacidad la posibilidad de decidir sobre su propia vida, como por ejemplo, el artículo $567^{\circ}, 570^{\circ}, 572^{\circ}$ y $573^{\circ}$ del Código Civil, lo que conlleva a reemplazar todo el esquema.

Tanto claro es la contradicción que el Juez del Tercer Juzgado de Familia de Cusco mediante Sentencia por Resolución № 32, de fecha 15 de junio de 2015, recaída en el Expediente № 01305201201001JRFC037, declaró inaplicable el inciso 2 del artículo 43 y los incisos 2 y 3 del artículo 44 del Código Civil referidos a la incapacidad civil absoluta y relativa, porque resultan incompatibles con el derecho a igual reconocimiento de la capacidad jurídica reconocido en el artículo 12 de la Convención sobre los derechos de las personas con discapacidad, a la igualdad ante la ley y los principios pro debilis, pro homine y de legalidad, contenidos en los artículos 3, 8, 24 y 25 de la Convención Americana de Derechos Humanos y los arts. 2.1., 2.2, 3, 7, 138 y 139 inc. 8 de la Constitución Política del Perú.

Claro está que ello no implica que las personas discapacitadas se les otorgue privilegios por encima de los otros, ya que en base a la igualdad deben tener los mismos derechos pero también los mismos deberes, esto quedo precisado por el Tribunal Constitucional en su Sentencia de fecha 25 de agosto de 2014, recaída en el Expediente N$^{\circ} 00393-2013-P A / T C{ }^{8}$, por el cual un comerciante discapacitado planteó una demanda de amparo para que se le permitiera comerciar al interior de un complejo turístico pese a que por disposición municipal se había prohibido dicho comercio, reubicando a todos los comerciantes.

Comité sobre los Derechos de las Personas con Discapacidad. Examen del informe presentado por el Perú en virtud de la Convención sobre los derechos de las personas con discapacidad. CRPD/C/PER/CO/1, 16 de mayo de 2012. Disponible en: http://webcache.googleusercontent.com/search?q=cache:a5-X9bvmZfMJ:www.ohchr.org/Documents/HRBodies/CRPD/7thsession/CRPD.C.PER.CO.1_sp.doc $+\& c d=1 \&$ hl=es\&ct=clnk\&gl=pe. Consultado el 25 de agosto de 2015 .

7 Disponible en: http://es.scribd.com/doc/270734369/Resolucion-N\%C2\%BA-32-Cusco-quince-de-Junio-Del-anodos-mil-quince. Consultado el 5 de setiembre de 2015.

8 Disponible en: http://www.tc.gob.pe/jurisprudencia/2014/00393-2013-AA.pdf. Consultado el 5 de setiembre de 2015. 
Ante tal situación, el Tribunal Constitucional estableció que no procedía obtener un beneficio de forma excluyente a razón de su incapacidad, además que respondía a un interés legítimo de la administración del lugar, descartando que se haya afectado derecho fundamental alguno y declararon infundada la demanda, aunque consideró que la administración debía adoptar "ajustes razonables" en favor del discapacitado.

\section{REFORMA DEL CÓDIGO CIVIL EN MATERIA DE CAPACIDAD: SISTEMA DE APOYO Y EL PROYECTO CEDIS}

Tanto la Convención sobre los Derechos de las personas con Discapacidad como la Ley № 29973, Ley General de la Persona con Discapacidad son tributarias del modelo social que reconoce la capacidad jurídica de las personas con discapacidad en igualdad de condiciones con las demás.

Dicha Ley realizó una serie de modificaciones sobre el Código Civil a fin de adecuar sus disposiciones al referido modelo respecto a las personas con deficiencia física. Sin perjuicio de lo anterior se ha verificado que subsiste una serie de dispositivos que en su gran mayoría sitúan a las personas con discapacidad o afectación mental como sujetos de interdicción y curatela.

En atención a lo anterior y a la necesidad de adecuar el Código Civil al modelo social incorporándose el Sistema de Apoyo y de ajustes razonables a todo artículo que hace referencia a la incapacidad se ha dispuesto por la Ley № 29973 citada una Comisión que se encargue de dicha reforma.

Resulta oportuno indicar que existen lineamientos básicos para el diseño del modelo de apoyo en la toma de decisiones de las personas con discapacidad siendo las siguientes:

a) Se debe partir de la premisa que las personas con discapacidad es un grupo diverso, por lo que el sistema de apoyo debe responder a dicha diversidad. "Por ejemplo, personas que pueden requerir apoyos pero quieren tomar la decisión por su cuenta sin designar formalmente un representante, y aquellos que pueden necesitar la asistencia de redes de representación para la toma de sus decisiones. La gente no necesariamente debiera requerir representantes o apoyos legalmente designados simplemente te porque un médico piense que son incapaces de tomar una decisión propia" (BACH, 2011, pp. 90-91). 
En esta medida, las medidas de apoyo deben ser proporcionales según la discapacidad de cada caso. En consecuencia, el juez deberá establecer obligatoriamente qué tipo de actos puede realizar por sí sola la persona con discapacidad, y en qué otros requerirá de alguien que lo auxilie, siendo estos supuestos los menos posibles, y no al revés como actualmente se hace.

b) La persona que asuma el rol de asistencia debe mantener un grado de confianza con la persona con discapacidad, dándose la prioridad a alguien de la familia salvo que la persona disponga lo contrario.

c) El concepto de apoyo es flexible que incluye una variedad de acuerdos de carácter formal e informal, acuerdos que pueden ser de distintas intensidades según los requerimientos de la persona que los solicita. Asimismo, "el tipo y la intensidad del apoyo que se ha de prestar variará notablemente de una persona a otra debido a la diversidad de las personas con discapacidad (...). En todo momento, incluso durante situaciones de crisis, deben respetarse la autonomía individual y la capacidad de las personas con discapacidad de adoptar decisiones". ${ }^{9}$.

d) Cuando cambie o desaparezca la discapacidad, las medidas de apoyo deberán modificarse para que sea un reflejo del estado físico y mental de la persona.

e) Durante el procedimiento respectivo, el juez deberá escuchar a la persona con discapacidad, a fin de que evalúe de forma directa la discapacidad en cuestión. Dicha persona, si así lo quiere, podrá ser asistida por alguien de su entera confianza.

f) El juez, al momento de evaluar el grado de discapacidad, deberá solicitar todos los informes que estime necesarios para contar con los elementos suficientes emitir su sentencia. Tales informes no deberán ser elaborados solo por médicos, sino también por pedagogos, abogados, sociólogos y demás expertos.

Finalmente, cabe precisar que la existencia de un sistema de apoyos y salvaguardias en el país no es sólo un tema de reforma en el Código Civil sino

Cfr. Comité CDPC. Proyecto de observación general sobre el artículo 12: igual reconocimiento como persona ante la ley. 25 de noviembre de 2013, párr. 15 y 16. Disponible en: http:/ / webcache.googleusercontent.com/search?q=cache:i7dCJyVGod4J:www.ohchr.org/Documents/HRBodies/CRPD/GC/DGCArticle12_sp.doc+\&cd=1\&hl=es\&c$\mathrm{t}=\mathrm{clnk} \& \mathrm{gl}=$ pe. Consultado el 01 de setiembre de 2015 . 
que también implica el diseño y la implementación de una política pública de Estado en todos los niveles, como se ha apreciado en la Ley $\mathrm{N}^{\circ} 29973$ citada, dejando de lado también términos que subestiman a las personas con discapacidad, señalándolos como "sujetos débiles" (GRONDONA, 2015, p. 64) o aluden a fraseos que en la misma línea se sigue la acción de protección y no de reconocimiento y apoyo, que son situaciones distintas, como aludir a "proteger los destellos de vida" de dichas personas (CIEZA, 2015, p, 186).

En tal sentido, la Comisión especial revisora del Código Civil en lo referente a la capacidad jurídica de la persona con discapacidad - CEDIS elaboró el Anteproyecto de Ley que modifica el Decreto Legislativo № 295 del Código Civil respecto al ejercicio de la capacidad jurídica y su implicancia en los libros de personas, acto jurídico, familia, sucesiones, contratos y prescripción y caducidad presentado al Congreso de la República generando el Proyecto de Ley № 04601, en el cual se le agrega sumillas que no contenía al anteproyecto. ${ }^{10}$

Los artículos que se plantean modificar son los siguientes: 1, 4, 5, 42-46, 140, 141, 156, 164, 243, 389, 564-568, 568-A, 569, 579, 595-609, 611, 615-618, 658, 687, 696 y 697. Asimismo, se propone derogar el numeral 2 del artículo 219, numeral 1 del artículo 221, numeral 2, 3 y 4 del artículo 241, numeral 1 y 2 del artículo 274, numerales 1-4 y 7 del artículo 277, numeral 1 del artículo 466, numeral 3 del artículo 599, numeral 2 del artículo 705, numeral 1, 5 y 6 del artículo 1994 del Código Civil.

De igual forma, derogar los artículos 3, 226-229, 570-578, 580-594, 610, 612, 613, 614 y 1358 del Código Civil.

Al respecto, se puede dudar si necesariamente se requiere modificar tantos artículos del Código Civil para adecuar una solo institución de las tantas desarrolladas en nuestro Código sustantivo, o realmente se trata en realidad

10 Esto fue observado por el Secretario Técnico del CEDIS porque consideraba que no debería sumillarse o poner subtítulos a los artículos del Código Civil que se pretenden modificar, ya que dicho Código no los tenía y que así debería quedarse, más allá de las imprecisiones colocadas como sumilla. Al respecto, se debe indicar que cuando se modifica los artículos del Código Civil o cualquier norma, se requiere poner epígrafes a dichos nuevos artículos, aun cuando el texto original no los haya tenido, y eso se tiene que hacer porque se está modificando el artículo bajo la vigencia de la Ley 26889, Ley Marco para la Producción y Sistematización Legislativa, que obliga a ponerlos (como ejemplo tenemos diversas leyes que han modificado el Código Civil y le han agregado epígrafes). En base a ello, era dable que al tramitarse el proyecto le hayan puesto epígrafes a los artículos propuestos, en atención a la técnica legislativa que dispone la Ley 26889, para que sean aprobados y publicados de dicho modo. Si bien la autógrafa del Decreto Legislativo № 295, Código Civil, no contiene sumillas o epígrafes; eso proviene a partir de la Ley № 25362 (año 1991) que autorizó “al Poder Ejecutivo para que en las ediciones oficiales de los Códigos Civil, Penal, Procesal Penal, de Ejecución Penal y del Medio Ambiente, así como las Leyes Orgánicas que considere pertinentes, se incluyan las sumillas correspondientes a cada artículo, y para la divulgación masiva de estos cuerpos legales en ediciones populares". Por ello el CEDIS debió seguir las reglas de técnica legislativa de dicha norma. 
de aprovechar la facultad de legislar una reforma del Código Civil para proponer cambios normativos en otros artículos que no están vinculados o podrían salvarse mediante interpretación.

Respecto a la parte sustancial del Proyecto CEDIS se sustituye la curatela por el de apoyos, salvaguardias y administración de bienes, definiendo a "los apoyos" como formas de asistencia en que la persona con discapacidad determina la forma, alcance y duración del apoyo que puede recaer en una o más personas naturales, instituciones públicas, o personas jurídicas sin fines de lucro, determinándose de manera excepcional por el juez. Dicha persona de apoyo debe garantizar las medidas accesibilidad y los ajustes razonables que se requieran para facilitar la capacidad de ejercicio de las personas con discapacidad.

En opinión personal, considerando que la discapacidad no es una categoría uniforme se proponen dos clases de sistemas de apoyo:

- Sistema de apoyo facultativo parcial.- Instituido a favor de las personas con discapacidad que pueden exteriorizar su voluntad pero que requieren la participación de un tercero para llevar a cabo los actos derivados de su decisión. En este caso no se sustituye la voluntad de la persona con discapacidad.

- Sistema de apoyo pleno obligatorio.- Esta modalidad es de carácter excepcional. Responde a los casos en que las personas con discapacidad física o mental no puedan expresar su voluntad por ningún medio o porque la exteriorización de la misma no refleja la voluntad deseable del sujeto debido a una afectación grave de su estado mental. En atención a ello, la prestación del apoyo es para la adopción de decisiones particulares en resguardo de sus derechos e intereses y en ningún caso trae como consecuencia el desconocimiento de su capacidad jurídica.

En base a esta situación, se determinará una serie de personas con un rango de prioridad y con vínculo afectivo para que sean seleccionadas por el Consejo de Familia como encargado de dar apoyo necesario en coordinación con dicho Consejo.

Sea cualquier situación modificatoria, se requiere modificar también el Código Procesal Civil para excluir de los supuesto de procedencia de la interdicción los referidos en el artículo 43 numeral 2 y en el artículo 44 numerales 2 y 3 del Código Civil. Estos debería ser incorporados en el Título 
III (Proceso Sumarísimo) de la Sección Quinta (Procesos Contenciosos) del Código como pretensiones propias del sistema de apoyo, desarrollándose sus supuestos de procedencia y los anexos específicos de la demanda a ser presentados.

\section{CONCLUSIONES Y REFLEXIONES}

El binomio absoluto de capacidad-incapacidad y el supuesto sinónimo de discapacidad e incapacidad, así como frases y términos que expresan proteger a "sujetos débiles" han sido cuestionados y deben ser suprimidos tanto en la legislación como en la doctrina, siendo lo correcto establecer protección a los derechos de las personas discapacitadas para establecer la igualdad con los que no tienen alguna discapacidad (cuestionada por la mayoría mundial, porque todo humano es deficiente en algún aspecto sin excepciones), promoviendo su desarrollo e inclusión plena y efectiva en la vida política, económica, social, cultural y tecnológica, como discapacitado, sin esperar a su curación (que algunas veces no es posible), conforme la Ley No 29973, Ley General de la Persona con Discapacidad, y en base a la Convención sobre los Derechos de las Personas con Discapacidad.

Para resulta atendible que se modifique el Código Civil que parte de un esquema contrario al modelo social actualmente imperante (y con justa razón), estableciendo que la persona discapacitada no debe ser objeto de reemplazo de su voluntad, no puede estar a merced de terceros aunque sean sus familiares (que pueden llevarse bien o no), no puede ser atacado sus actos de autonomía privada con nulidad o anulabilidad por el mero hecho de tener alguna deficiencia mental o física, ya que no obsta a que siga ejerciendo sus derechos de manera idónea, como lo hace o hacía John Nash (fallecido hace poco en mayo de 2015) que era un matemático estadounidense, especialista en teoría de juegos, geometría diferencial y ecuaciones en derivadas parciales, que recibió el Premio Nobel de Economía en 1994 y Stephen William Hawking que es un físico teórico, astrofísico, cosmólogo y divulgador científico británico, que se hace cargo en el marco de sus posibilidades de sus actividades, entre otras muchas personas que dejan a su discapacidad como un mero escollo que a veces suele olvidarse, y nosotros tenemos que hacer lo mismo. 


\section{REFERENCIAS BIBLIOGRÁFICAS}

Falzea, Angelo (1985) Capacità. En: Voci di Teoria General di diritto. Terza edizione. Milano: Giuffrè Editore.

Oertmann, Paul (1933) Introducción al Derecho Civil. Traducción del alemán por Luis Sancho Real. Barcelona-Buenos Aires: Editorial Labor.

Larenz, Karl (1978) Derecho Civil. Parte General. Traducción del alemán por Miguel Izquierdo y Macías-Picavea. Jaén: Editorial Revista de Derecho Privado, 1978.

Cariota Ferrara, Luigi (1956) El negocio jurídico. Traducción del italiano por Manuel Albaladejo García. Madrid: Aguilar.

Coviello, Nicolas (1938) Doctrina General del Derecho Civil. Traducción del italiano por Felipe de J. Tena. México: Unión Tipográfica Editorial HispanoAmericana.

Gazzoni, Francesco (1998) Manuale di Diritto Privato. VII edizione aggiornata. Napoli: Edizioni Scientifiche Italiane.

Alpa, Guido y Bessone, Mario (1990) Elementi di Diritto Civile. Milano: Giuffrè Editore, 1990.

Paradiso, Massimo (2012) Corso di Istituzioni di Diritto Privado. Settima edizione. Torino: G. Giappichelli Editore.

Espinoza Espinoza, Juan (2004) Derecho de las Personas. 4ta Edición. Lima: Gaceta Jurídica, 2004.

Flume, Werner (1998) El Negocio Jurídico. Parte General del Derecho Civil. Cuarta edición. Traducción del alemán por José María Miquel González y Esther Gómez Calle. Madrid: Fundación Cultural del Notariado.

León Barandiarán, José (1991) Tratado de Derecho Civil. Tomo I. Lima: WG Editor.

Bigliazzi, Lina; Breccia, Humberto; Natolli, Ugo; Busnelli, Francesco (1995) Derecho Civil. Normas, sujetos y relación jurídica. Tomo I. Volumen 1, Traducción del italiano por Fernando Hinestrosa: S/C: Departamento de Publicaciones de la Universidad Externado de Colombia. 
Bariffi, Francisco (2011) Capacidad jurídica y discapacidad: una visión del Derecho Comparado. En: Capacidad Jurídica, Discapacidad y Derechos Humanos. Una revisión desde la Convención Internacional de los Derechos delas Personas con Discapacidad. Buenos Aires: EDIAR.

Quinn, Gerard (2011) Personalidad y capacidad jurídica: Perspectivas sobre el cambio de paradigma del artículo 12 de la CDPD. En: Bariffi, Francisco y Palacios, Agustina. Capacidad jurídica, discapacidad y derechos humanos. Una revisión desde la Convención Internacional sobre los Derechos de las Personas con Discapacidad. Buenos Aires: Ed. EDIAR.

Bach, Michael (2015) El derecho a la capacidad jurídica en la Convención de la ONU sobre los derechos de las personas con discapacidad: conceptos fundamentales y lineamientos para una reforma legislativa. Disponible en: $\quad$ http://archivo.eluniversal.com.mx/graficos/pdf14/Bach $\% 20-\% 20$ Capacidad Juridica. pdf. Consultado el 20 de agosto.

Espinoza Espinoza, Juan (2012) Derecho de las Personas. Lima: Gaceta Jurídica.

Fernandez Sessarego, Carlos (1995) El histórico problema de la capacidad jurídica. En: Diez años del Código Civil peruano. Balance y perspectivas. Actas del Congreso Internacional. Lima: Universidad de Lima.

Priori Posada, Giovanni (2004) La capacidad como presupuesto negocia". En: Negocio Jurídico y responsabilidad civil. Estudios en memoria del profesor Lizardo Taboada Córdova. Lima: Grijley.

Grondona, Mauro (2015) Sujetos débiles y medidas de protección en la experiencia italiana. En: Actualidad Civil. Enero. № 7. Lima: Instituto Pacífico.

León Hilario, Leysser (2015) Parte subjetivamente compleja, indivisibilidad y anulabilidad por incapacidad relativa. La norma más oscura del Código Civil también cumple treinta años (¿y dice adiós?). En: Gaceta Civil \& Procesal Civil. Tomo 20. Febrero. Lima: Gaceta Jurídica.

Cieza Mora, Jairo (2015) La discapacidad mental y la necesidad de una regulación más humanitaria en el Perú. Una mirada desde el Derecho de Personas. En: Gaceta Civil \& Procesal Civil. Tomo 24. Junio. Lima: Gaceta Jurídica. 
